(c) 2017, Elsevier. Licensed under the Creative Commons Attribution-NonCommercialNoDerivatives 4.0 International

http://creativecommons.org/licenses/by-nc-nd/4.0/

\title{
Non-invasive biomedical research and diagnostics enabled by innovative compact lasers.
}

\author{
Karina S. Litvinova*1, Ilya E. Rafailov², Andrey V. Dunaev³, Sergei G. Sokolovski ${ }^{1}$, \\ Edik U. Rafailov ${ }^{1}$
}

${ }^{1}$ Optoelectronics and Biomedical Photonics Group, Aston Institute of Photonic Technologies, Aston University, Birmingham, UK² School of Engineering and Applied Science, Aston Institute of Photonic Technologies, Aston University, Birmingham, UK

${ }^{3}$ Orel State University named after I.S. Turgenev, Scientific-Educational Center "Biomedical Engineering", Orel, Russia

* k.litvinova@aston.ac.uk; e.rafailov@aston.ac.uk 


\begin{abstract}
For over half a century, laser technology has undergone a technological revolution. These technologies, particularly semiconductor lasers, are employed in a myriad of fields. Optical medical diagnostics, one of the emerging areas of laser application, are on the forefront of application around the world. Optical methods of non- or minimally invasive bio-tissue investigation offer significant advantages over alternative methods, including rapid real-time measurement, non-invasiveness and high resolution (guaranteeing the safety of a patient). These advantages demonstrate the growing success of such techniques.

In this review, we will outline the recent status of laser technology applied in the biomedical field, focusing on the various available approaches, particularly utilising compact semiconductor lasers. We will further consider the advancement and integration of several complimentary biophotonic techniques into single multimodal devices, the potential impact of such devices and their future applications. Based on our own studies, we will also cover the simultaneous collection of physiological data with the aid a multifunctional diagnostics system, concentrating on the optimisation of the new technology towards a clinical application. Such data is invaluable for developing algorithms capable of delivering consistent, reliable and meaningful diagnostic information, which can ultimately be employed for the early diagnosis of disease conditions in individuals from around the world.
\end{abstract}

Keywords: compact laser, non-invasive diagnostics, multifunctional laser diagnostics, microcirculation, tissue oximetry, autofluorescence 


\section{Introduction.}

Revolution in laser technology, particularly semiconductor lasers, over the past 55 years has led to the widespread expansion of advanced photonics in many areas of science and technology. Laser diodes have found many applications in diverse fields: telecommunications, data storing, welding, cutting and micromachining, etc. During this time, we have also significantly improved our understanding of light interaction with biomaterials at the molecular level, further expanding our knowledge of bioprocesses in vivo/in situ. The main targets of modern photonic research in biomedicine can be formulated as the development of effective and reliable approaches capable of non- and minimally-invasively discriminating healthy and diseased conditions at their earliest stage, when they can most easily be treated and cured [1]. These approaches combined with wireless technology will eventually facilitate personalised medicine.

Currently, the leading causes of death among the worldwide population are cardiovascular diseases (CVDs) and cancer. The number of heart attack cases, for example, will more than double in the next 15 years. Similar increases have been projected for the number of newly discovered cancer cases[2]. It is well documented that early diagnosis of cancer as well as heart disease is associated with improved prognosis[3,4]. Meeting all these challenges will require new methods and devices with which, ideally, diseases can be caught and fought. Newest optical technologies are well suited to fill this need, based on collecting scattered or fluorescent light from tissue and measuring changes in the amplitude, wavelength, and polarisation state that result from the onset and progression of disease.

The continuously spreading and improving compact semiconductor laser technology has found many potentially groundbreaking applications. As such, in this paper we will review the recent status of such technology applied in biomedicine, particularly in distinguishing pathologies/normality and further diagnostics. One main application area for these optical techniques are CVD and cancer diagnostics. When conditions of pathology are present, the absorption, scattering, fluorescence and Raman scattering properties often undergo significant changes due to alterations in tissue composition and morphology, blood perfusion and metabolic activity [5]. There are several promising areas of optical approaches for medical diagnostics being developed around the world - laser coherent and diffusive wave tomography/imaging, spectroscopy of elastic scattering, fluorescence tissue spectroscopy, laser Doppler flowmetry, tissue oximetry and a number of other techniques. The first prototype devices are already marketed for medical application. Optical methods of bio-tissue investigation have significant advantages like non-invasiveness and high resolution in comparison to conventional methods. Thus, techniques displaying these advantages have demonstrated huge success within clinical diagnostics[6]. The full non-invasiveness of the optical scanning techniques include, among other approaches, well known confocal ophthalmoscopy[7] and optical coherent tomography[8] to investigate internal tissue microstructure at a spatial resolution of 10-15 $\mu \mathrm{m}$ without significant damage (depth of $2 \mathrm{~mm}$ ), and Doppler flowmetry for monitoring cardio-vascular physiological rhythms and blood microcirculation[9]. Tissue oximetry together with laser Doppler flowmetry (including the cerebral vascular system)[10] work in real time, allowing for the study of physiological rhythms, dynamic processes in microcirculatory systems and oxygen transport in tissues under various function stress tests - occlusion, temperature, pharmacological, etc. The unique capability of in vivo fluorescence spectroscopy to register and analyse many lifelong maintained endogenous fluorescent substances (autofluorophores) in tissues and organs[11,12] can be seen as a specific niche of the technique in broader medical application. Much like autofluorescence, Raman spectroscopy[13] also allows for non-invasive measurement without the need for exogenous labels.

Thus, optical methods of bio-tissue investigation can be used as navigation and guidance towards diseased areas on a macroscopic level. Photonics based techniques can be used to identify suspected 
areas. Microscopic approaches like nonlinear autofluorescence/harmonic imaging and OCT can then be employed to obtain an optical biopsy in vivo to confirm the disease with high specificity.

In the review, we will also broadly discuss standard detection methodologies reliant on compact laser sources and their major limitations, before covering photonics based techniques for early tumour detection and staging, assessing their diagnostic accuracy for flat and precancerous changes[14].

We will consider the advancement and integration of biophotonic technologies in multimodal devices, towards realising meaningful diagnostic biomarkers relevant to developing integral algorithms capable of delivering consistent and reliable data with utility in clinical practice for early diagnosis of disease conditions such as cancers and cardio-vascular diseases.

\section{Light propagation in tissue.}

The use of lasers in biology and medicine is based on the exploitation of a wide range of phenomena associated with the various manifestations of biological objects with light interaction. The unique properties of the laser beam opened opportunities of its application. Figure 1 shows the classification of the basic principles on laser use in various fields of surgery, therapy and diagnosis, taking into account the specified process group, there are three types of effects:

1. Photodestructive effect impact, in which the thermal, hydrodynamic and photochemical effects of light cause tissue destruction. This kind of interaction may be observed in laser surgery.

2. Photophysical and photochemical effects, in which the light absorbed by biological tissues excites the atoms and molecules, causing photochemical and photophysical reactions. These effects often find applications as therapeutics.

3. Nonperturbing impact, when biotissue does not change its properties during the interaction with light. These are effects such as scattering, reflection and penetration. This type is employed for diagnostics.

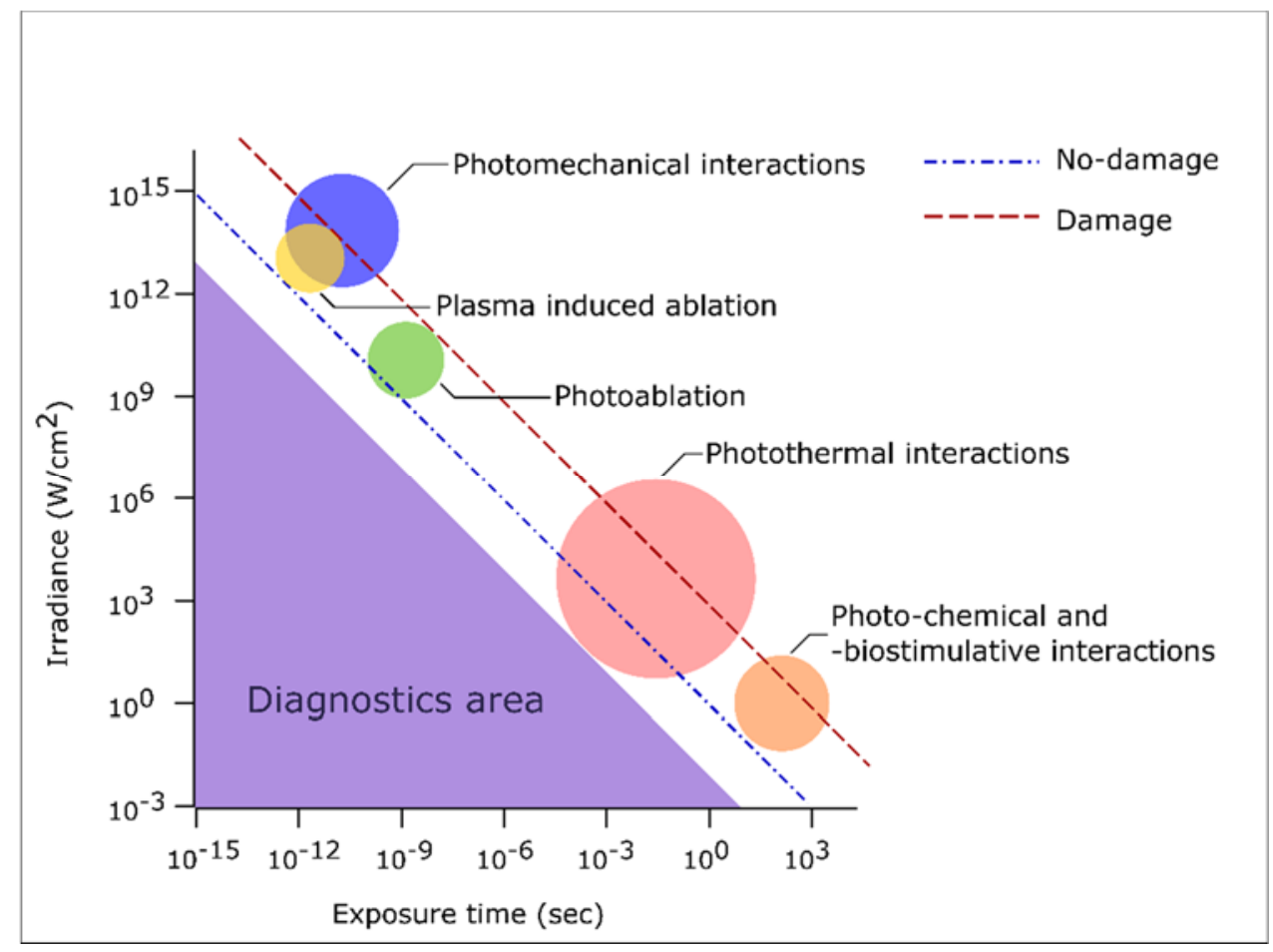


Figure 1. Basic principles on laser use. The coloured circles designate interactions between tissue and light resulting in structural changes. The area below these circles indicates the optimal area for developing diagnostics techniques and technologies (adapted from previous light-tissue interaction schemes $[15,16])$.

Photobiological effects depend on the parameters of laser radiation: wavelength, beam intensity of light energy, time of exposure to biological tissue. From the point of view of physical method application research, the area of low intensity light presents itself as one of greatest interest. Some of the most sensitive physical methods can be employed with the help of low intensity light, as they do not require a strong light output and, therefore, due to the homeostasis of living matter, do not introduce distortion to the measurement results even at a local level[17].

Considering the above, it is important to understand the basis of laser radiation application in biomedicine. It relies on the fact that all organic macromolecules (proteins, nucleic acids and polysaccharides), all the basic elements of blood, most lipids and amino acids, nucleotides along with their precursors and other biochemical components of cells exhibit characteristic spectra of optical absorption, reflection, scattering and luminescence. These spectra differ for oxidised and reduced states of molecular components, with the ratio of the various forms and concentrations of these components within the investigated area determined by the overall functional activity of numerous cell structures and organelles, including erythrocytes (red blood cells). Considering that biological tissues are an optically non-uniform absorbing media, spatial morphology (in particular the cell membranes, epithelial and endothelial cell layers) significantly influences the integral optical properties. Thus, absorption and scattering are two of the fundamental optical processes that can be exploited for diagnostic information without modifying or damaging the investigated tissues[18]. It is well known, however, that the latter processes are not the only potential light-tissue interactions; that light can interact with biological objects in numerous ways. A portion of the optical radiation is reflected while others may also be passed through the various layers of biological tissue.

Fundamentally, light-tissue interactions are processes of elastic scattering (single scattering and diffuse scattering), absorption, fluorescence, and Raman scattering[18,19]. Figure 2 illustrates an incident ray that is transmitted into the bio-tissue. By measuring Doppler shift, backscattering light, absorption and autofluorescence signals from a sample, a "biophotonic pattern" of the sample (tissue/cells) may be inferred, allowing recognition of normal and pathological conditions. 


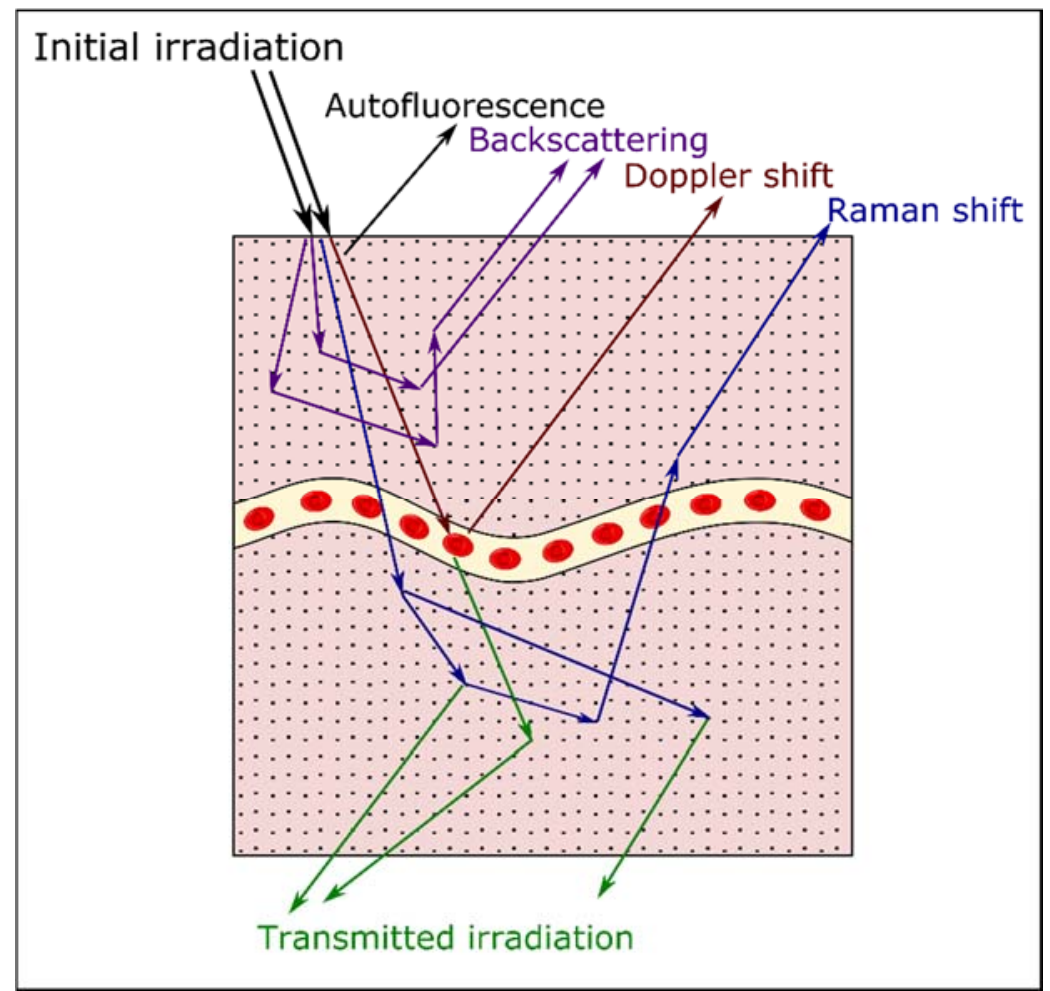

Figure 2. Schematic of light-tissue interactions.

The nature of optical radiation interaction with biological tissues is also determined by its penetration power. Various layers of bio-tissue unequally absorb optical radiation of differing wavelength. Here, we will focus on processes that occur at wavelengths in the 300-1500 nm range, spanning the ultraviolet (UV), visible and near infrared (NIR) regions of the spectrum (Figure 3 ). In this range, the electronic structure of matter is the most relevant, since electrons predominantly interact with these electromagnetic waves. The light penetration depth increases when moving from UV radiation to the NIR range from $100 \mu \mathrm{m}$ to few $\mathrm{mm}$, while the picture is made more complicated due to the domination of water absorption at the mid and far IR ranges[19,20]. The penetration depth of radiation in biotissue, with an intensity sufficient for clinically significant photobiochemical and thermodynamic effects, depends on the presence and concentration ratio of the three major photochromes (water, fat, melanin and haemoglobin), the wavelength and the radiation power along with its associated temporal-spatial characteristics. 


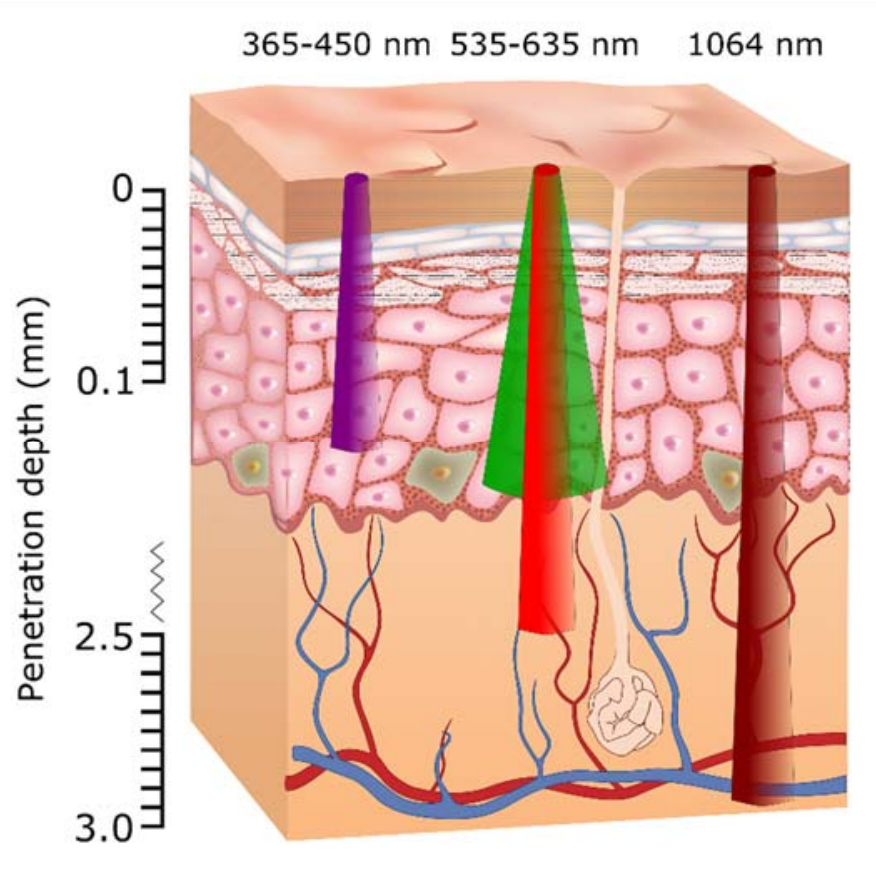

Figure 3. Simplified representation of penetration depth of UV, visible (green) and NIR radiation into a section of human skin.

It is also important to understand the effects of certain endogenous molecules upon the path of light through tissue. Oxygenated and deoxygenated haemoglobin[21], beta-carotene[22] and melanin (in skin) $[23,24]$ act as the principal absorbers of visible light in human tissue. Scattering of visible light in this medium is largely attributed to collagen fibres and sub-cellular organelles[25]. The presence of autofluorophores underlies a number of techniques (such as fluorescence spectroscopy) that will be discussed further in the review. These endogenous molecules, upon excitation by a specific wavelength, will re-emit the light as fluorescence at a longer wavelength[26].

Thus, with the aid of low intensity laser radiation, easily and cheaply provided by continuously developing laser diodes and LEDs, it is possible to investigate the processes occurring in living objects without seriously disturbing their behaviour. It is important to note that successful application of lasers in medical diagnostics largely depends on the choice of laser source and the means of radiation delivery to the biological object. All biomedical laser applications require certain parameters to be fulfilled. These can be, for example, wavelength, output power, beam quality, size and cost-efficiency of the laser systems. Within the past few decades, a variety of instrumental developments, primarily new lasers, detectors and methods have expanded the utility of spectroscopy for biomedical applications. Compact laser sources have proven their superior performance in stable line excitation over a range of wavelengths in the UV/visible (GaN based LED and laser diodes)[27], Red and Near IR (GaAs based lasers)[28,29], IR (InP, GaSb and QCL based lasers)[28,30-32] regions.

\section{Optical approaches in diagnostics.}

The application of optical imaging methods, as opposed to regular biopsies, suggests that tissue is not removed or modified in any way (for example, for histological analysis). Instead, one or another form of non- or minimally-invasive optical measurement is carried out on the tissue with the aim of providing an on-site, real time, in vivo diagnosis. 
Non-invasive optical approaches can solve many problems in diagnostics. Biophotonic applications of systems based on compact semiconductor lasers range from diagnostics and imaging applications such as optical coherence tomography (OCT)[33], fluorescence lifetime imaging[34], tissue oximetry[35], diffuse optical imaging[36], THz imaging[37] or laser Doppler imaging[38], to treatments[39,40]. For example, in dermatology, ophthalmology, gynaecology, gastroenterology and neurosurgery, optical methods are promising for diagnosis, localisation and treatment of malignant neoplasms, photodynamic therapy of various diseases, mammography and imaging of the skin and internal organs[5]. Transscleral photocoagulation of tissues in the eyeball (ciliary body, retina, etc.) is widely used in ophthalmology for the treatment of glaucoma, retinal detachment and other diseases[41]. Optical methods are used to monitor the functional activity of the brain, heart, vascular system function, determining the rate of blood flow and lymph flow, blood volume in tissues and its degree of oxygenation[1]. Modern biophotonic techniques offer many potential technological advances, such as diagnosis and prevention of diseases; identification of chronic disease risk factors; earliest stage disease diagnostics; health monitoring.

\section{In vivo confocal and multi-photon microscopy}

In vivo confocal laser scanning microscopy (CLSM) resembles histological tissue evaluation, except that 3D subcellular resolution is achieved noninvasively and with or without external labelling. In epithelial structures, resolutions of $1 \mu \mathrm{m}$ have been achieved with a $200-400 \mu \mathrm{m}$ field of view[42]. While this technology can provide detailed images of tissue architecture and cellular morphology, a very small field of view and limited penetration depth of 250-500 $\mu \mathrm{m}$ considerably reduce the clinical usefulness of this approach[43]. The ability of the photosensitisers to accumulate in cancer cells and to fluoresce under specific wavelengths can be used to identify and delineate areas of microscopic changes[44,45].

Multi-photon laser scanning microscopy (MLSM) is one technique, in which the fluorophore excitation results from visible or longwave infrared range lasers. MLSM resolutions are comparable to those obtained from a CLSM system. However, due to their reliance on IR excitation, they circumvent a number of the problems associated with the latter technique. For example, a greater penetration depth is possible because of the reduced scattering at these wavelengths[46-48]. Furthermore, in these techniques, the nonlinearly excited fluorescence is confined to a point around the focal volume (where the intensities are the highest) and simultaneously exhibits intrinsic optical sectioning capabilities, limiting any possible photo-damage effects, such as photo-bleaching. Thus, two-photon excited fluorescence (TPEF) with depth penetration up to $1 \mathrm{~mm}$ has found multiple uses in tasks such as the monitoring of membrane potential, selective non-linear electrophysiological process optical sensing , protein dynamics recording inside living cells, in vivo morphogenesis imaging etc. [49]. Finally, these techniques can additionally generate contrast through nonlinear scattering processes[50] such as Second-Harmonic Generation (SHG) and Third-Harmonic Generation (THG). This gives the possibility of providing label free (minimally invasive) contrast generation. SHG can be observed in well-defined and highly arranged non-centrosymmetric structures such as collagen, muscle and microtubules [51] whereas THG is observed when the focused ultra-short beam finds an interface. THG imaging has been successfully used to image live processes from various model organisms such as Caenorhabditis elegans (C. elegans), Drosophila melanogaster and Danio rerio, containing different structures such as lipid droplets, cell boundaries, tissues etc[52-57].

Optical coherent tomography (OCT) - a modern non-invasive, high -resolution (15 $\mu \mathrm{m})$ method of live bio-tissue structural imaging at a depth of $1.5-2 \mathrm{~mm}$. The principle basis of the method, analogous to ultrasound, relies on the use of near IR light in a range of $800-1300 \mathrm{~nm}$ as the probe radiation[58,59]. Both technologies employ back-scattered signals reflected from different layers within the tissue to reconstruct structural images, with the latter measuring sound rather than light. The resulting OCT 
image is a two-dimensional representation of the optical reflection within a tissue sample. The method allows for real time tissue imaging. OCT is employed for investigation of thin layers of skin, as well as mucous membranes of the eyes and dental tissues. It allows the study of blood vessel structure without removing or excising tissue samples. Thus, OCT has become a well-established tool for biomedical research and clinical diagnostics[60]. It is further utilised in many other fields of medical and biological research. For example, it is regularly used for the early detection and treatment monitoring of retinal pathologies[61]. Another clinical application is examining atherosclerotic plaques and coronary stents in cardiac blood vessels with endoscopic OCT systems[62]. Numerous studies have sought to investigate the diagnostic utility of in vivo OCT to detect and diagnose oral pre-malignancy and malignancy[63,64], bladder cancer[65,66], skin cancers such as BCC etc. [67].

Elastic scattering spectroscopy (ESS) or diffuse reflectance spectroscopy is an in vivo, non-invasive optical diagnosis technique sensitive to changes in the physical properties of human tissue and thus able to detect early cancerous and precancerous changes $[68,69]$. ESS measured in the visible and near IR ranges of the electromagnetic spectrum is a cheap, fast and simple-to-use tool compared to other spectroscopic techniques. It is sensitive to the changes in the physical properties of tissue such as nuclear size, density and changes in the nucleus. Predominately, ESS provides information about the morphology and absorption of the stroma. A physically based mathematical model to extract the haemoglobin concentration, oxygen saturation, average diameter, and density of scatters may be employed to analyse ESS. These physical parameters have been actively used non-invasively and in real-time to distinguish dysplasia (early cancerous or precancerous state)[70].

Raman scattering provides detailed molecular information about the tissue. Raman spectroscopy detects photons that have been inelastically scattered. Inelastic scattering means that the frequency of photons in monochromatic light changes upon interaction with sample molecules. The difference in energy corresponds to a molecular vibration of a component of the specimen[71]. The observed change in photon energy (i.e. optical frequency) and wavelength is specific to the molecular vibration from which the photon was Raman-scattered. Raman shift effect provides information about vibrational, rotational and other low frequency transitions in molecules. Several studies have investigated the utility of Raman spectroscopy in diagnosing cancer and CVD diseases[72-74]. For example, some of these studies have focused on the examination of ex vivo tissues (biopsy studies) due to the lack of Raman probe availability. After showing the relevance of examining biopsied tissues, the feasibility of in vivo Raman spectroscopic point measurements of pathological tissues was displayed by using an early Raman probe, during routine clinical endoscopy[75,76].

Laser Doppler flowmetry (LDF), since its commercialisation in the early 1980s, has provided an everincreasing approach to non-invasive measurement of haemodynamics; allowing for measurements to avoid the use of radioactive markers employed in earlier techniques[38,77,78]. The technique relies upon the delivery of NIR laser radiation into a segment of tissue being scattered by constituent tissue molecules. The motion of an erythrocyte within the microcirculatory system imparts a Doppler frequency shift on the photons being scattered. As a result, a range of Doppler shifts is obtained due to the orientation of microvessels in living tissue and the continuous stream of erythrocytes. A photodetector ultimately registers the scattered radiation. This allows for a continuous measurement of tissue perfusion based on the Doppler shifted and non-shifted photons registered by the photodetector. Due to these principles, LDF suffers from oversensitivity to motion and a reliance on arbitrary "perfusion units", limiting clinical use. However, especially in conjunction with other techniques such as tissue oximetry, LDF has been successfully employed for physiological research[79,80], cancer research[81-83], plastic surgery[84], clinical perfusion monitoring in Raynaud's syndrome and diabetes and many other tissue and organ investigations[85].

Tissue oximetry (TO) is a technique employed for the non-invasive in vivo monitoring of system microhaemodynamics[86]. It is capable of determining the oxygen transport and utilisation in a tissue. 
The underlying principle relies on the comparison of different values of haemoglobin fractions within the measured tissue's microvascular blood volume $[87,88]$. Using spectrophotometric analysis, this technique measures microvascular systems containing varying levels of both oxygenated and deoxygenated haemoglobin[79], each of which has unique absorption characteristics detected by green $(530 \mathrm{~nm})$ and red $(635 \mathrm{~nm})$ wavelength ranges respectively. While still not clinically widespread, this technique is commonly found in research environments. Furthermore, as stated above, in conjunction with LDF and other optical methodologies, tissue oximetry is a powerful tool capable of providing non-invasive measurements of parameters such as oxygen consumption within a living tissue[79].

Fluorescence spectroscopy (FS) can be used to observe biochemical properties. It relies upon light of a specific wavelength being delivered to tissue. When this light is absorbed, it may excite endogenous molecules known as fluorophores, which then re-emit the light as fluorescence at a longer wavelength[26]. The re-emitted light that returns to the tissue surface is detected and sent to a spectrometer or spectrograph to produce a wavelength-resolved fluorescence spectrum[89]. The reemitted fluorescence can also be time-resolved, or measured as a combination of wavelength- and time-resolved data[90]. Fluorescence photons are, however, known to be scattered and absorbed during their path to the tissue surface where they are collected via the optical fibre probe. Therefore, the spectral features of the collected fluorescence can be significantly distorted, making the extraction of tissue biochemical composition from the measured signal difficult. This is a particular problem in the presence of strong tissue absorbers such as haemoglobin[91,92].

Fluorescence measurements provide information about the relative contents of endogenous tissue fluorophores such as collagen, keratin, elastin, carotene and lipopigments, porphyrins, NADH and FAD $[93,94]$ (Figure 4). Despite its limitations, it has been applied to detect atherosclerosis of the aorta and coronary arteries[95,96], cervical dysplasia[97], adenomatous colon polyps[98], dysplasia in the oesophagus[99], oral cavity dysplasia and multiple forms of cancer (e.g. urinary bladder, breast, lung etc.) $[81,93,100,101]$. The urinary bladder cancer cells were detected using redox ratio and double excitation wavelengths of autofluorescence (AF)[45]. One of the greatest advantages of this methodology for AF analysis of cells is in the high throughput of cells, thereby enabling the generation of redox overviews and the direct comparison of different populations of cells. We demonstrated obvious differences in the redox overviews of cancerous and healthy cells, thereby suggesting that diagnostic thresholding based on this data is possible[102]. 


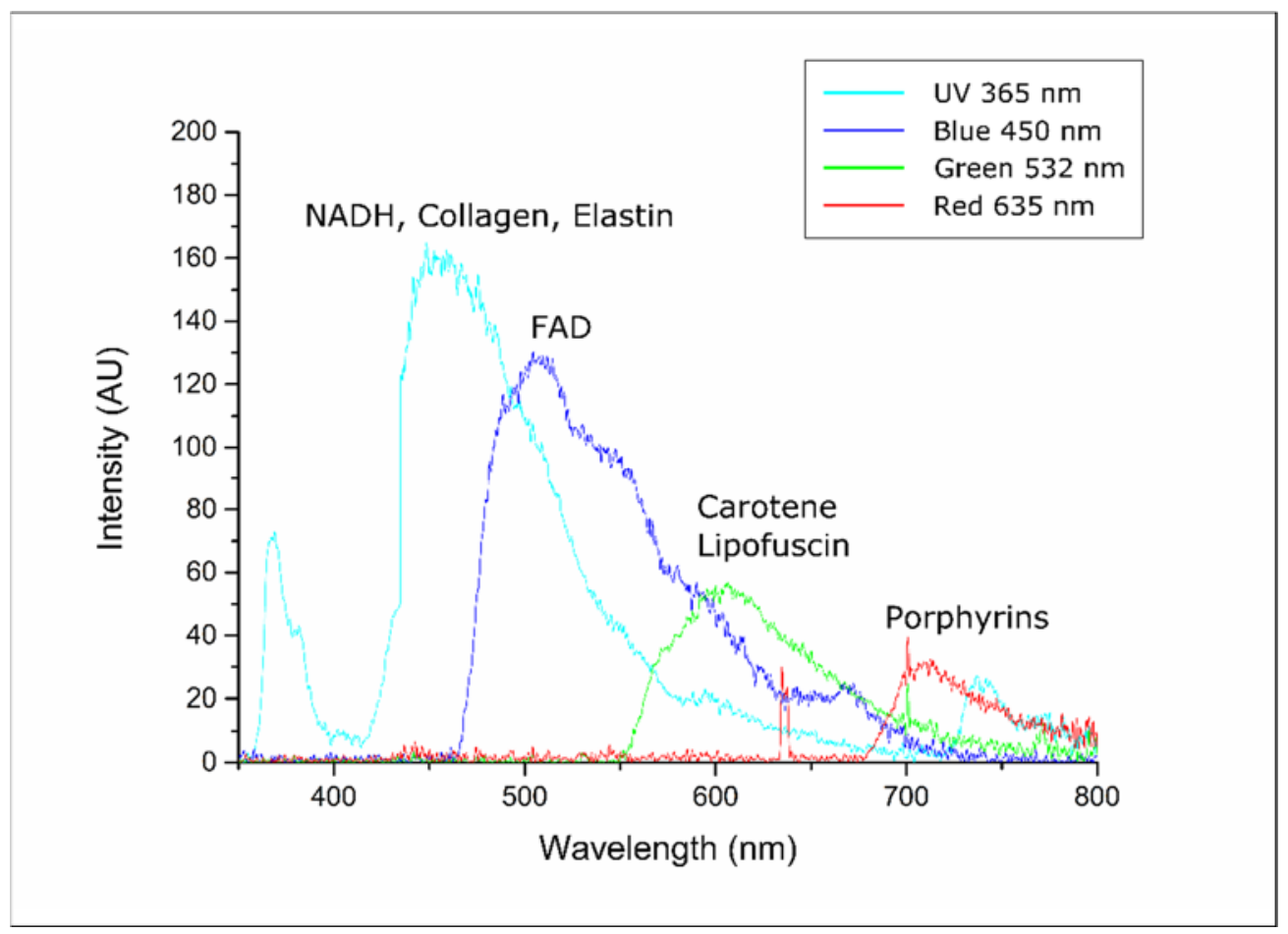

Figure 4. Example of skin fluorescence spectra resulting from 365, 450, 532 and $635 \mathrm{~nm}$ wavelength excitation. Major autofluorophores are labelled above their respective spectra[103,104].

\section{Multifunctional laser diagnostic system for non-invasive medical laser Doppler flowmetry and spectroscopy.}

While the above-mentioned non-invasive techniques provide detailed structural and biochemical information, they generally offer less quantitative information related to the clinical diagnostics[105107]. Individually, in some cases, methods have been limited by the lack of efficiency[108]. For example, recorded fluorescence methods strongly depend on the absorption (haemoglobin, oxyhaemoglobin, melanin etc.) and scattering (microstructure properties of biological tissues' depth and surface, level of blood supply, water content) parameters[24,94,106,109-113]. The capacity for diagnoses may be significantly improved by combining different methods and techniques. The advent of easily accessible, compact semiconductor based lasers[48] makes the combination of such methods and techniques, previously large and expensive, possible.

Based on this information, we will focus on new techniques, which have been developed to combine various spectroscopic modalities to distinguish grades of pathological tissue by simultaneously determining biochemical, structural, and morphological information. The question remains, however, which optical method to use? It is already common in medical and surgical practice to use commercial devices for optical pulse oximetry and LDF or laser Doppler (LD) perfusion monitoring[114] as well as fluorescence diagnostics[115], optical coherence and diffusion tomography[6,116], bio-tissue fat detection, blood glucose, haemoglobin and oxyhaemoglobin analysis[117]. Furthermore, devices combining two or more such techniques are also becoming available for use [118]. These combinations allow therapists and clinicians to not only receive the arithmetic sum of the diagnostic information that could be collected by each individual method, but also to conduct multifunctional patient examination measurements to identify subtle individual characteristics of blood flow and 
tissue metabolism using simultaneous and comprehensive data from different diagnostic techniques[108,119].

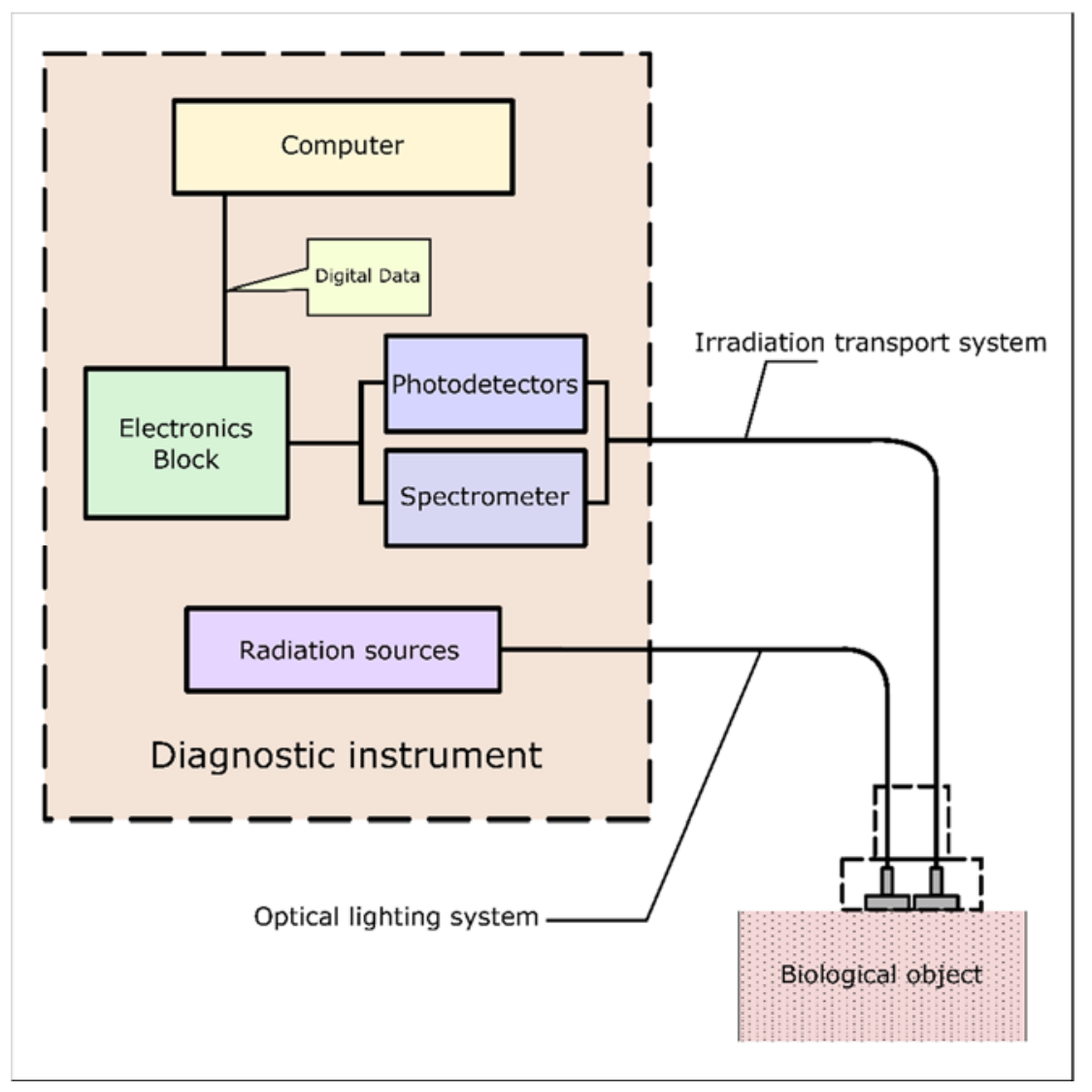

Figure 5. A simplified block schematic of the multifunctional noninvasive diagnostics unit LAZMA (LAZMA SPE). This device combines the LDF, tissue oximetry, pulse oximetry and FS techniques. Key components to device function are labelled.

The dynamic development of optical spectroscopic methods used in clinical practise gave birth to multifunctional laser non-invasive diagnostic systems (MLNDS). One such multifunctional device is the LAKK-M (Figure 5)[120]. It allow the study of a number of microcirculatory parameters, including blood microcirculatory index $\left(\mathrm{I}_{\mathrm{m}}\right)$ (by LDF) and oxygen saturation $\left(\mathrm{StO}_{2}\right)$ of skin tissue (by tissue reflectance oximetry, TO). Over the course of a few years, preliminary in vivo studies by Dunaev et al[79] show the results of using the combined techniques of the LAKK-M[121]. The device apparatus includes a fibre-optic system to allow analysis at selected points on the body. Large LDF and TO data arrays underwent wavelet analysis to highlighted regulatory rhythms in the vascular system. The ability to study synchronisation of microvascular blood flow and oxygen saturation rhythms under normal and adaptive change conditions using this device was presented.

Research results demonstrated the emergence of resonance and synchronisation of microvascular blood flow and oxygen saturation rhythms as an adaptive change in myogenic oscillation (vasomotion) resulting from exercise and potentially from psychoemotional stress (Figure 6). Synchronisation of myogenic rhythms during adaptive changes suggests increased oxygen consumption resulting from increased microvascular blood flow velocity. 


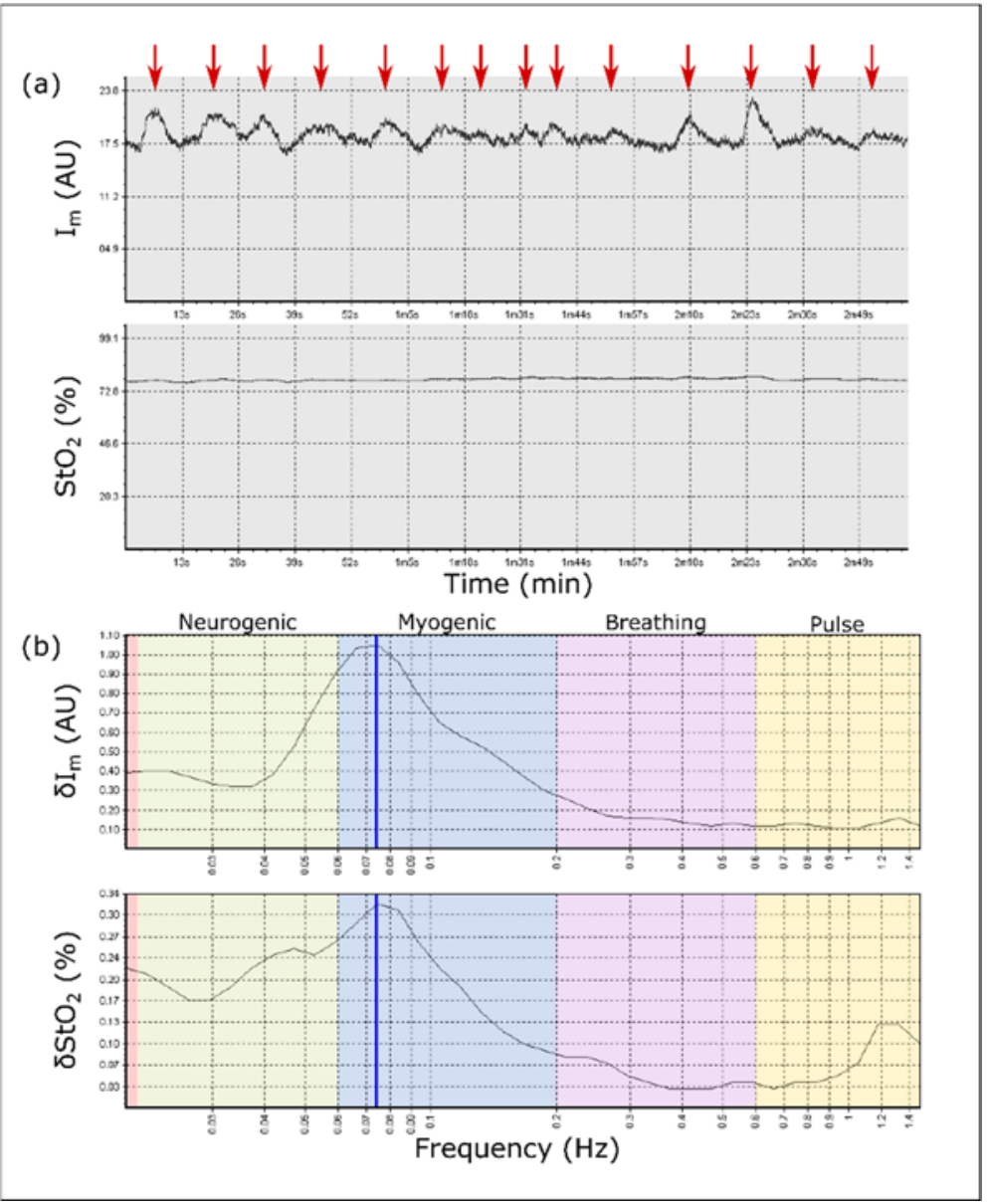

Figure 6. (a) Perfusion and oxygen saturation graphs. Cases of myogenic oscillation are indicated by $a \downarrow$. (b) Example of microvascular blood flow and oxygen saturation resonance and synchronised rhythms within the range of myogenic oscillation (vasomotion) during adaptive changes.

Dunaev et al. also aimed to assess individual variability of endogenous marker (NADH, FAD, etc.) fluorescence parameters measured in situ by FS and to analyse the factors that lead to a significant scatter of results[79]. Both LDF and TRO data was collected, followed by detection of the fluorescence spectra all at the same volume sampling point (Using the 365 and $450 \mathrm{~nm}$ wavelengths as depicted in Figure 4). Evidence that the level of blood volume in tissue affects the FS data with a significant inverse co-relation was provided. The fluorescent redox ratio (FRR), defined as the ratio of the fluorescence intensity of NADH to FAD [85,122-125], was further calculated.

To expand the methodological and metrological background of multifunctional diagnostics devices, further studies were also conducted. The effects of various physiological (skin melanin content) and technical (optical filter characteristics) factors on the measurement results were observed. It was proved, that the intensity of the backscattered radiation is highly dependent on the blood supply to the skin, which is likely to change during pathological processes in tissues, and thus provide additional diagnostic information. The effect of the skin melanin on the measured parameters in areas with and without arteriovenous anastomoses was recorded on volunteers of different ethnic skin types including Caucasian, Indian, Middle Eastern and African (with a range of melanin content approximately from $1.3 \%$ to $43 \%$ ). The oxygen transport in microvasculature was calculated for each 
volunteer. The respiration in tissue was estimated by the Oxygen Metabolism Efficiency (OME) complex parameter

$$
O M E=M \cdot \frac{\mathrm{SaO}_{2}}{\mathrm{StO}_{2}} \cdot \mathrm{FRR}
$$

Where $M$ is the average of perfusion units $\left(I_{m}\right)$ and FRR the fluorescence redox ratio. The index of tissue oxygen consumption rate, a parameter that characterises the specific oxygen consumption per unit of blood volume in the tissue region under the optic probe as defined by Krupatkin \& Sidorov[9] is also present, signified by the ratio of arterial to total saturation[126,127].

The presented results show a near $100 \%$ absorption of the visible spectrum in the pigmented skin area compared to the informative fluorescence spectra obtained in the un-pigmented zone. Nevertheless, a weakly informative fluorescence spectrum was obtained in the pigmented zone using the red excitation laser as a result of the weaker melanin absorption in this region. It was concluded that dermal spectroscopy can be potentially useful in the assessment of differences in melanin content of skin pigmentation changes in vivo and furthermore, that such data can potentially be of utility in calculating, using appropriate algorithms, the corrected relative amplitude of fluorescent signals.

Thus, using MLNDS such as the LAKK-M, allows for the calculation of a multi-parametric indicator of tissue oxygen consumption OME. This is potentially a more informative complex parameter for in vivo laser based tissue investigation than the primary parameters of blood microcirculatory condition. $I_{\mathrm{m}}$, $\mathrm{Vr}, \mathrm{SaO}_{2}$, and $\mathrm{StO}_{2}$ are much more variable and demonstrate individual/specific physiological condition of the tissue at a particular time moment.

The results also indicate a defined relationship between NADH and FAD, suggesting its use as a potentially very stable baseline parameter in the calculation of complex parameters. The complex approach to this allows physicians to receive complementary data about micro-haemodynamics, oxygen consumption and condition of metabolic processes for their interpretation and decision making concerning disease diagnosis. It is important to note that patient data from different sex, age and health conditions is required to establish and validate a baseline OME.

Despite the plethora of diagnostics devices available commercially, developed for tissue research and diagnostics, there is no developed and standardised methodology to monitor the real time conditions of living organisms. To expand and strengthen the monitoring capacity of multifunctional devices, we used the LAKK-M, to non-invasively assess animal conditions during experiments and treatment. It was noted that cholesterol feeding induced CVD by cardiac hypertrophy in wild-type mice[128]. The LAKK-M was chosen to carry out non-invasive analysis of skin autofluorescence biomarkers relevant to cardiovascular disease in mice. Mice on regular and high cholesterol diets were observed. The LAKK-M optical probe was used to make simultaneous measurements of collagen, elastin, NADH, pyridoxine, flavins, lipofuscin and $\beta$-carotene on the test animals. A reduction was observed in pyridoxine, NADH, flavins, lipofuscin and $\beta$-carotene, which are established risk factors for cardiovascular disease. Based on the above results, we presented a novel optical technique for the non-invasive assessment of preeclampsia in an in vivo mouse model relevant to oxidative stress by means of the LAKK-M. These experimental studies evaluated the tissue blood perfusion and oximetry methods, as well as the content of coenzymes NADH and FAD in order to determine the monitoring capacity on live animals[129]. Preliminary experiments were conducted on mice with adenoviral mediated overexpression of sFlt-1 (Ad-sFlt-1) to mimic preeclampsia-like symptoms [130]. By measuring a number of key physiological characteristics $\left(\mathrm{I}_{\mathrm{m}}, \mathrm{SO}_{2}, \mathrm{NADH}\right.$ and FAD fluorescence) and subsequently calculating further parameters (including the previously described $\mathrm{OME}$ ), 
microcirculatory and metabolic changes were observed after Ad-sFlt-1 treatment of animals, as well as between virus treated and CMV control animals. Moreover, this study proved that LAKK-M monitoring is effective on anaesthetised and un-anaesthetised animals, providing flexibility in terms of future application.

In terms of clinical application, the first blood perfusion and NADH/FAD content combined analysis results have been obtained in patients with diabetic foot[85]. Skin blood microcirculation and the metabolism activity of tissue were examined on the patients with type 2 diabetes. A two-stage experiment was completed on a type 2 diabetic patient population and matched controls. A number of tests, including cold and hot functional tests, were employed. . The high sensitivity at detecting irregularities in the haemodynamic and metabolic processes of the biological tissue in type 2 diabetes was shown using modifications of the specific features of FS and LDF perfusion monitoring. Studies of the patients' endocrinological profile noted that this proposed original method could be used to diagnose disorders of the microvasculature and metabolism in the lower limbs of patients at the early stages of the disease.

In recent years, FS induced by laser excitation has been used in the study of a wide range of diseases[12,45,100,131,132]. Development of cancer involves a series of changes, some of which can be probed by FS[93]. Consistent fluorescence differences have been detected between normal, precancerous and cancerous spectra $[26,93,133]$. However, as tissue is a complex medium and fluorophores are known to interact with one another, diagnostic information from individual fluorophores can often be lost[1,6]. As mentions earlier, tissue refraction, scattering parameters (internal and surface microstructural properties of biological tissue, level of blood supply, water content) and absorption (hemoglobin, oxyhemoglobin etc.) may significantly affect tissue fluorescence[134]. These are important quantities necessary to describe the transport and intensity of light through tissue. As an aid to photonics based diagnostics, we designed and developed a computational 3D urinary bladder model to allow for the study of light propagation by a wide range of wavelengths through bio-tissue[135]. Pig bladder tissues were subjected to optical analysis by the FS of the LAKK-M device. For the construction of the 3D model, experimentally obtained transmission and diffuse reflectance values were utilised to calculate transport coefficients of tissue. Absorption and scattering coefficient spectra were constructed using the inverse adding-doubling method based modelling[136] (Figure 7). It should be noted that while this particular model was based on an excised organ, standard values from literature were used to account for the water content and blood flow within the measured tissue segments. This provision allows for the model to fully exploit the functionality of multifunctional devices in determining optical and microvascular properties, if used in conjunction on living organic tissue. 

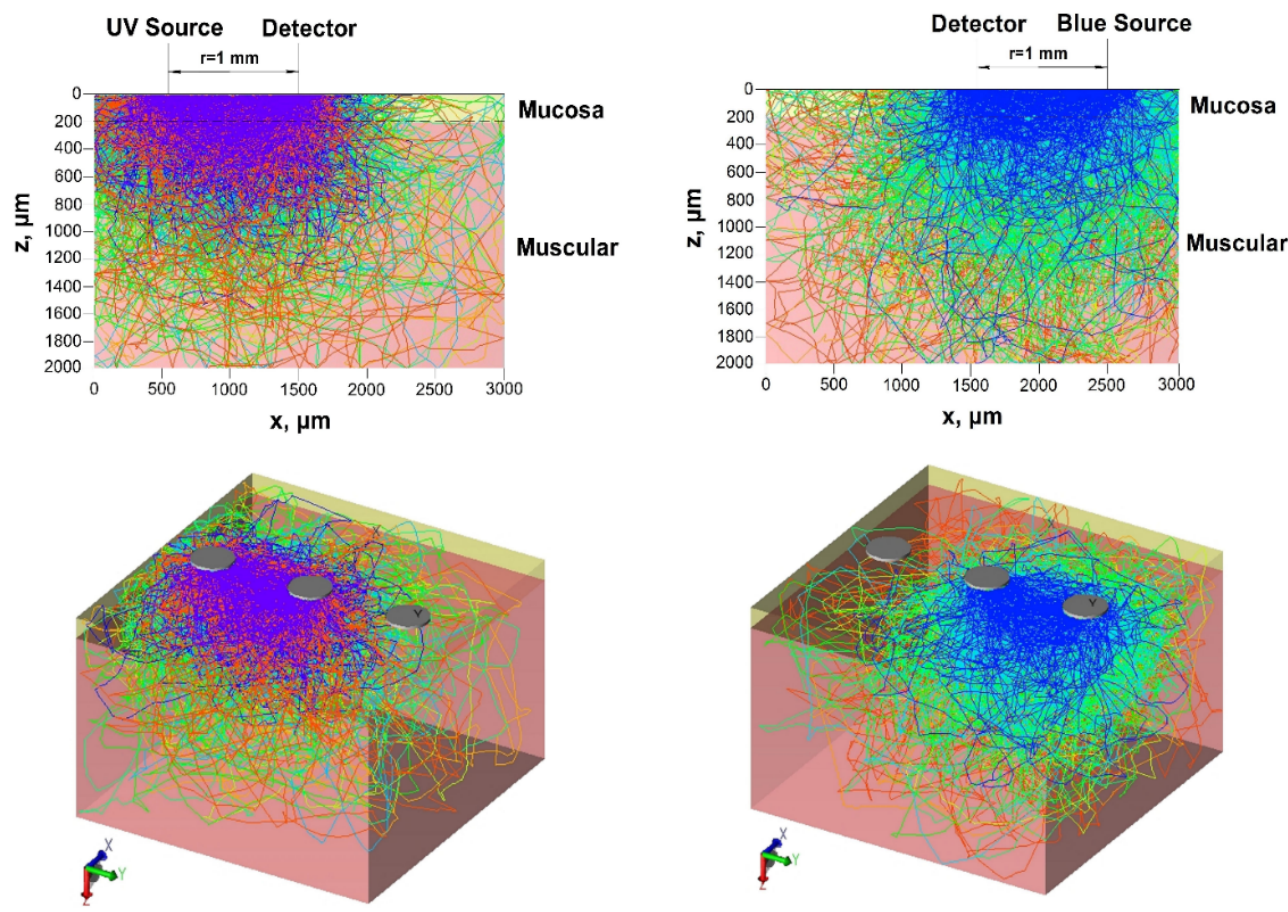

a

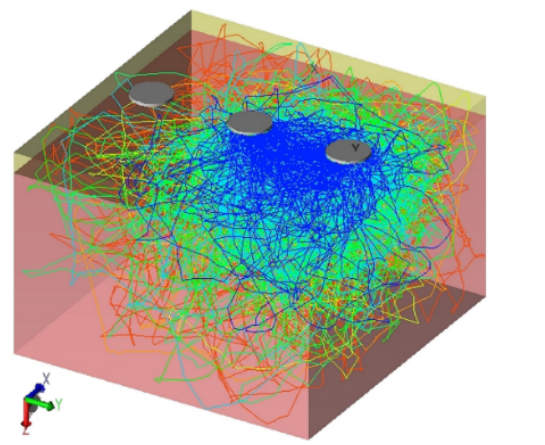

b

Figure 7. (a) Side and 3D view of the model, displaying simulated UV light within tissue. (b) Side and 3D view of model displaying simulated Blue light within tissue. The source, detector and the tissue layers are labelled. The passage of individual photons through the tissue is indicated by the lines.

Based on our results, we can therefore conclude that the modelling allows for the collection of data on the absorption of the fluorescence radiation. Considering these data, it is possible to analyse realtime fluorescence spectra for the accumulation of different fluorophores. Fluorescence changes of biochemicals such as NADH and collagen will provide details about urinary bladder tissue biochemistry[137-139]. Additionally, based on the developed optical model and further computer simulations, the general distribution of light within tissue can be predicted. This can be invaluable in a variety of non-invasive optical investigation methods, and their subsequent early validation. Ultimately this can lead to potential new avenues for diagnostics. Furthermore, modelling can provide a standardised reference point tailored to each individual undergoing photonics based diagnosis. In combination with such diagnostics, earlier detection of diseases such as cancer may become possible. Integration of such software based analysis with the previously described multifunctional monitoring and diagnostics presents itself as the next step in photonics based diagnostics.

Here, we have tried to reveal the potential of MLNDS at providing clinicians with useful, easily understandable information on the condition of patients. Specifically, the ability to simultaneously record and combine a wealth of information, rather than carry out many individual analysis using different spectroscopic tools and technologies. While real time human measurements will always vary from tissue to tissue, organ to organ or person to person, such multifunctional analyses allow for the minimisation of errors that stem from individual use of the described methods. A more accurate picture can be painted using the combination of methods and analytical techniques as described above. 


\section{Future perspectives of multi-functional laser diagnostics.}

In the next few years, non-invasive technology will have revolutionised medicine. The future prospects for MLNDS are the development of high performance compact laser sources that, at a low cost, will individually or in hybrid format, cover virtually any spectral band required for laser diagnostics.

In the future, diagnostics will migrate from the clinic to the home and workplace where advanced technical solutions integrating multiple scientific advances will provide early warning of disease risk and onset. It is easy to imagine major global diseases such as CVD, cancer and type 2 diabetes being detected and diagnosed much earlier, more conveniently and at a lower cost than is possible today. Modern photonics based systems can be minimised down to watch size and can monitor human health condition, while wirelessly sending this information to your PC and practitioner. Thus, wearable devices and ever-improving smartphones can serve as the hub for new diagnostic and treatment technologies. Therefore, anyone, anywhere (working or gym), at any time (during exercise or sleep) can obtain the necessary information about their condition.

With the possibilities for miniaturisation of technology available today and in the future, the possibility of the Star Trek Tricorder as used by Dr McCoy to quickly scan and diagnose patients becomes a serious prospect (@Paramount Home Entertainment). Going one step further, the capacity for therapy within the same small device is also within our reach.

\section{Acknowledgments}

We would like to thank Dr Victor V. Sidorov of SPE "LAZMA," Moscow, Russia, for his fruitful contributions to discussions on many of the topics covered in this review. The research was partially supported by grant "MESO-BRAIN" (No. 713140) of Europe Union's H2020, FET-open scheme. 
References:

[1] Tuan Vo-Dinh., ed., Biomedical Photonics Handbook, Second Edition: Biomedical Diagnostics, 2014.

[2] F. Bray, A. Jemal, N. Grey, J. Ferlay, D. Forman, Global cancer transitions according to the Human Development Index (2008-2030): a population-based study., Lancet. Oncol. 13 (2012) 790-801. doi:10.1016/S1470-2045(12)70211-5.

[3] WHO, Global status report on noncommunicable diseases 2014, World Health. (2014) 176. doi:ISBN 9789241564854.

[4] J.W. Petersen, C.J. Pepine, Microvascular Coronary Dysfunction and Ischemic Heart Disease Where Are We in 2014?, Trends Cardiovasc. Med. 25 (2015) 98-103. doi:10.1016/j.tcm.2014.09.013.

[5] D. Boas, C. Pitris, N. Ramanujam, eds., Handbook of Biomedial Optics, CRC Press, Boca Raton, 2011.

[6] V. V Tuchin, ed., Handbook of Optical Biomedical Diagnostics, Second Edition: 2-Volume Set (Vols. PM262 and PM263), SPIE Press, Bellingham, WA, 2016.

[7] R.H. Webb, G.W. Hughes, F.C. Delori, Confocal scanning laser ophthalmoscope, Appl. Opt. 26 (1987) 1492-1499. doi:10.1364/AO.26.001492.

[8] F. LaRocca, D. Nankivil, S. Farsiu, J.A. Izatt, True color scanning laser ophthalmoscopy and optical coherence tomography handheld probe, Biomed. Opt. Express. 5 (2014) 3204-3216. doi:10.1364/BOE.5.003204.

[9] S.V.V. Krupatkin A.I., Laser Doppler Flowmetry of Blood Microcirculation, Meditcina-, Moscow, 2005.

[10] D. Coca, Y. Zheng, J.E.W. Mayhew, S.A. Billings, Nonlinear system identification and analysis of complex dynamical behavior in reflected light measurements of vasomotion, Int. J. Bifurc. Chaos. 10 (2000) 461-476.

[11] G. a Wagnieres, W.M. Star, B.C. Wilson, In Vivo Fluorescence Spectroscopy and Imaging for Oncological Applications, Photochem. Photobiol. 68 (1998) 603-632. doi:10.1111/j.17511097.1998.tb02521.x.

[12] O.D. Smirnova, D. a. Rogatkin, K.S. Litvinova, Quantitative Fluorescent Biomarkers of Abnormal Tissue Changes, J. Innov. Opt. Health Sci. 5 (2012) 1250010. doi:10.1142/S1793545812500101.

[13] P. Matousek, E.R.C. Draper, A.E. Goodship, I.P. Clark, K.L. Ronayne, A.W. Parker, Noninvasive Raman Spectroscopy of Human Tissue in vivo, Appl. Spectrosc. . 60 (2006) 758-763. http://asp.sagepub.com/content/60/7/758.abstract.

[14] J.D.C.J.H. Colin E Webb, Handbook of Laser Technology and Applications, 2004.

[15] V.S. Letokhov, Laser biology and medicine, Nature. 316 (1985) 325-330. doi:10.1038/316325a0.

[16] V. Tuchin, Tissue Optics and Photonics: Light-Tissue Interaction II, J. Biomed. Photonics Eng. 2 (2016) 30201. doi:10.18287/JBPE16.02.030201.

[17] J. Popp, V. V. Tuchin, A. Chiou, S.H. Heinemann, eds., Handbook of Biophotonics, Volume 1: Basics and Techniques, WILEY-VCH Verlag GmbH \& Co. KGaA, Weinheim, 2011. 
[18] V. V Tuchin, S.R. Utz, I. V Yaroslavsky, Tissue optics, light distribution, and spectroscopy, Opt. Eng. 33 (1994) 3178-3188. http://dx.doi.org/10.1117/12.178900.

[19] V. V. Tuchin, Tissue Optics, Light Scattering Methods and Instruments for Medical Diagnostics, Third Edition, SPIE Press, Bellingham, WA, 2015.

[20] T.A. Henderson, L.D. Morries, Near-infrared photonic energy penetration: can infrared phototherapy effectively reach the human brain?, Neuropsychiatr. Dis. Treat. 11 (2015) 2191-208. doi:10.2147/NDT.S78182.

[21] S.L. Jacques, Optical properties of biological tissues: a review., Phys. Med. Biol. 58 (2013) R3761. doi:10.1088/0031-9155/58/11/R37.

[22] G. Romano, A. Conti, A. Gnerucci, P. Imperiale, F. Fusi, Laser-tissue interaction principles : tissue optical properties in the light therapeutic window ( invited review ), (n.d.).

[23] A.N. Bashkatov, E.A. Genina, V. V Tuchin, Optical properties of skin, subcutaneous, and muscle tissues: a review, J. Innov. Opt. Health Sci. 4 (2011) 9-38. doi:10.1142/S1793545811001319.

[24] V. V Dremin, A. V Dunaev, How the melanin concentration in the skin affects the fluorescence-spectroscopy signal formation, J. Opt. Technol. 83 (2016) 43-48. doi:10.1364/JOT.83.000043.

[25] R.H. Wilson, M. Chandra, J. Scheiman, D. Simeone, B. McKenna, J. Purdy, M.-A. Mycek, Optical spectroscopy detects histological hallmarks of pancreatic cancer, Opt. Express. 17 (2009) 17502-17516. doi:10.1364/OE.17.017502.

[26] N. Ramanujam, Fluorescence spectroscopy in vivo, in: Encycl. Anal. Chem., 2000: pp. 20-56. doi:10.1002/9780470027318.a0102.pub2.

[27] S.P. DenBaars, D. Feezell, K. Kelchner, S. Pimputkar, C.-C. Pan, C.-C. Yen, S. Tanaka, Y. Zhao, N. Pfaff, R. Farrell, M. Iza, S. Keller, U. Mishra, J.S. Speck, S. Nakamura, Development of galliumnitride-based light-emitting diodes (LEDs) and laser diodes for energy-efficient lighting and displays, Acta Mater. 61 (2013) 945-951. doi:http://dx.doi.org/10.1016/j.actamat.2012.10.042.

[28] N.N. Ledentsov, V.A. Shchukin, Y.M. Shernyakov, M.M. Kulagina, A.S. Payusov, N.Y. Gordeev, M. V Maximov, N.A. Cherkashin, (In,Ga,Al)P-GaP laser diodes grown on high-index GaAs surfaces emitting in the green, yellow and bright red spectral range, Semicond. Sci. Technol. 32 (2017) 25016. doi:10.1088/1361-6641/aa5144.

[29] A. Wunsch, K. Matuschka, A Controlled Trial to Determine the Efficacy of Red and NearInfrared Light Treatment in Patient Satisfaction, Reduction of Fine Lines, Wrinkles, Skin Roughness, and Intradermal Collagen Density Increase, Photomed. Laser Surg. 32 (2014) 93100. doi:10.1089/pho.2013.3616.

[30] S. Stephan, D. Frederic, A. Markus-Christian, Novel InP- and GaSb-based light sources for the near to far infrared, Semicond. Sci. Technol. 31 (2016) 113005. doi:10.1088/0268$1242 / 31 / 11 / 113005$.

[31] G. Duxbury, N. Langford, K. Hay, N. Tasinato, Quantum cascade laser spectroscopy: diagnostics to non-linear optics, J. Mod. Opt. 56 (2009) 2034-2048. doi:10.1080/09500340903349955.

[32] Y. Yao, A.J. Hoffman, C.F. Gmachl, Mid-infrared quantum cascade lasers, Nat Phot. 6 (2012) 432-439. http://dx.doi.org/10.1038/nphoton.2012.143. 
[33] A.M. Zysk, F.T. Nguyen, A.L. Oldenburg, D.L. Marks, S. a Boppart, Optical coherence tomography: a review of clinical development from bench to bedside, J. Biomed. Opt. 12 (2007) 51403. doi:10.1117/1.2793736.

[34] K. Suhling, L.M. Hirvonen, J.A. Levitt, P.-H. Chung, C. Tregidgo, A. Le Marois, D.A. Rusakov, K. Zheng, S. Ameer-Beg, S. Poland, S. Coelho, R. Henderson, N. Krstajic, Fluorescence lifetime imaging (FLIM): Basic concepts and some recent developments, Med. Photonics. 27 (2015) 340. doi:10.1016/j.medpho.2014.12.001.

[35] S. Hyttel-Sorensen, T.W. Hessel, G. Greisen, Peripheral tissue oximetry: comparing three commercial near-infrared spectroscopy oximeters on the forearm, J. Clin. Monit. Comput. 28 (2014) 149-155. doi:10.1007/s10877-013-9507-9.

[36] R.X. Xu, S.P. Povoski, Diffuse optical imaging and spectroscopy for cancer, Expert Rev. Med. Devices. 4 (2007) 83-95. doi:10.1586/17434440.4.1.83.

[37] M.-A.B. and F.F. and A.Y. and M.S. and N.A. and Y. Eishii, Terahertz imaging applied to cancer diagnosis, Phys. Med. Biol. 55 (2010) 4615. http://stacks.iop.org/0031-9155/55/i=16/a=001.

[38] V. Rajan, B. Varghese, T.G. van Leeuwen, W. Steenbergen, Review of methodological developments in laser Doppler flowmetry, Lasers Med. Sci. 24 (2009) 269-283. doi:10.1007/s10103-007-0524-0.

[39] S.G. Sokolovski, S. a Zolotovskaya, a Goltsov, C. Pourreyron, a P. South, E.U. Rafailov, Infrared laser pulse triggers increased singlet oxygen production in tumour cells., Sci. Rep. 3 (2013) 3484. doi:10.1038/srep03484.

[40] F. Anquez, I. El Yazidi-Belkoura, S. Randoux, P. Suret, E. Courtade, Cancerous Cell Death from Sensitizer Free Photoactivation of Singlet Oxygen, Photochem. Photobiol. 88 (2012) 167-174. doi:10.1111/j.1751-1097.2011.01028.x.

[41] P.A. Bloom, S. Dharmaraj, Endoscopic and transscleral cyclophotocoagulation, Br. J. Ophthalmol. 90 (2006) 666-668. doi:10.1136/bjo.2005.082073.

[42] W.G. (Jay) J. Robert L. Price, Basic Confocal Microscopy, 2011. doi:10.1007/978-0-387-781754.

[43] N.S. Allen, D.T. Brown, Dynamics of the endoplasmic reticulum in living onion epidermal cells in relation to microtubules, microfilaments, and intracellular particle movement, Cell Motil. Cytoskeleton. 10 (1988) 153-163. doi:10.1002/cm.970100120.

[44] A.A. Rosenkranz, D.A. Jans, A.S. Sobolev, Targeted intracellular delivery of photosensitizers to enhance photodynamic efficiency, Immunol. Cell Biol. 78 (2000) 452-464. doi:10.1046/j.1440-1711.2000.00925.x.

[45] S. Palmer, K. Litvinova, E.U. Rafailov, G. Nabi, Detection of urinary bladder cancer cells using redox ratio and double excitation wavelengths autofluorescence, Biomed. Opt. Express. 6 (2015) 977. doi:10.1364/BOE.6.000977.

[46] C. Xu, W. Zipfel, J.B. Shear, R.M. Williams, W.W. Webb, Multiphoton fluorescence excitation: new spectral windows for biological nonlinear microscopy., Proc. Natl. Acad. Sci. U. S. A. 93 (1996) 10763-10768. http://www.ncbi.nlm.nih.gov/pmc/articles/PMC38229/.

[47] A.T. Yeh, N. Nassif, A. Zoumi, B.J. Tromberg, Selective corneal imaging using combined second-harmonic generation and two-photon excited fluorescence, Opt. Lett. 27 (2002) 2082-2084. doi:10.1364/OL.27.002082.

[48] E.U. Rafailov, ed., The Physics and Engineering of Compact Quantum Dot-based Lasers for 
Biophotonics, 2014.

[49] W.A. Mohler, J.G. White, Multiphoton laser scanning microscopy for four-dimensional analysis of Caenorhabditis elegans embryonic development., Opt. Express. 3 (1998) 325-331. doi:10.1364/OE.3.000325.

[50] L. Moreaux, O. Sandre, M. Blanchard-Desce, J. Mertz, Membrane imaging by simultaneous second-harmonic generation and two-photon microscopy, Opt. Lett. 25 (2000) 320-322. doi:10.1364/OL.25.000320.

[51] S. Psilodimitrakopoulos, D. Artigas, G. Soria, I. Amat-Roldan, A.M. Planas, P. Loza-Alvarez, Quantitative discrimination between endogenous SHG sources in mammalian tissue, based on their polarization response, Opt. Express. 17 (2009) 10168-10176. doi:10.1364/OE.17.010168.

[52] R. Aviles-Espinosa, S.I.C.O. Santos, A. Brodschelm, W.G. Kaenders, C. Alonso-Ortega, D. Artigas, P. Loza-Alvarez, Third-harmonic generation for the study of Caenorhabditis elegans embryogenesis, J. Biomed. Opt. 15 (2010) 46020-46027.

http://dx.doi.org/10.1117/1.3477535.

[53] D. Débarre, W. Supatto, E. Farge, B. Moulia, M.-C. Schanne-Klein, E. Beaurepaire, Velocimetric third-harmonic generation microscopy: micrometer-scale quantification of morphogenetic movements in unstained embryos., Opt. Lett. 29 (2004) 2881-3. doi:10.1364/OL.29.002881.

[54] W. Supatto, D. Débarre, B. Moulia, E. Brouzés, J.-L. Martin, E. Farge, E. Beaurepaire, In vivo modulation of morphogenetic movements in Drosophila embryos with femtosecond laser pulses., Proc. Natl. Acad. Sci. U. S. A. 102 (2005) 1047-52. doi:10.1073/pnas.0405316102.

[55] E.J. Gualda, G. Filippidis, M. Mari, G. Voglis, M. Vlachos, C. Fotakis, N. Tavernarakis, In vivo imaging of neurodegeneration in Caenorhabditis elegans by third harmonic generation microscopy, J Microsc. 232 (2008) 270-275. doi:JMI2098 [pii] \r10.1111/j.13652818.2008.02098.x.

[56] S.-W. Chu, T.-M. Liu, C.-K. Sun, C.-Y. Lin, H.-J. Tsai, Real-time second-harmonic-generation microscopy based on a 2-GHz repetition rate Ti:sapphire laser, Opt. Express. 11 (2003) 933938. doi:10.1364/OE.11.000933.

[57] C.-K. Sun, S.-W. Chu, S.-P. Tai, S. Keller, U.K. Mishra, S.P. DenBaars, Scanning secondharmonic/third-harmonic generation microscopy of gallium nitride, Appl. Phys. Lett. 77 (2000) 2331. doi:10.1063/1.1316776.

[58] B.E. Bouma, G.J. Tearney, Handbook of Optical Coherence Tomography, Marcel Dekker, 2002. http://www.imalux.com/documents/HandbookofOpticalCoherenceTomography.pdf.

[59] W. Drexler, J.G. Fujimoto, eds., Optical Coherence Tomography Technology and Applications, Springer International Publishing, 2015.

[60] P. Wilder-Smith, J. Holtzman, J. Epstein, A. Le, Optical diagnostics in the oral cavity: an overview, Oral Dis. 16 (2010) 717-728. doi:10.1111/j.1601-0825.2010.01684.x.

[61] S. Saidha, S.B. Syc, M.A. Ibrahim, C. Eckstein, C. V. Warner, S.K. Farrell, J.D. Oakley, M.K. Durbin, S.A. Meyer, L.J. Balcer, E.M. Frohman, J.M. Rosenzweig, S.D. Newsome, J.N. Ratchford, Q.D. Nguyen, P.A. Calabresi, Primary retinal pathology in multiple sclerosis as detected by optical coherence tomography, Brain. 134 (2011) 518-533. doi:10.1093/brain/awq346.

[62] P.W.S. Evelyn Regar, A.M.G.J. van Leeuwen, Optical Coherence Tomography in Cardiovascular 
Research, 2007.

[63] P. Wilder-Smith, K. Lee, S. Guo, J. Zhang, K. Osann, Z. Chen, D. Messadi, In Vivo Diagnosis of Oral Dysplasia and Malignancy Using Optical Coherence Tomography: Preliminary Studies in 50 Patients, Lasers Surg. Med. 41 (2009) 353-357. doi:10.1002/Ism.20773.

[64] C.-K. Lee, T.-T. Chi, C.-T. Wu, M.-T. Tsai, C.-P. Chiang, C.-C. (C C. Yang, Diagnosis of oral precancer with optical coherence tomography, Biomed. Opt. Express. 3 (2012) 1632-1646. doi:10.1364/BOE.3.001632.

[65] A. Karl, H. Stepp, E. Willmann, A. Buchner, Y. Hocaoglu, C. Stief, S. Tritschler, Optical coherence tomography for bladder cancer - ready as a surrogate for optical biopsy? - Results of a prospective mono-centre study, Eur. J. Med. Res. 15 (2010) 131-134. doi:10.1186/2047783X-15-3-131.

[66] R. Drake, Bladder cancer: Optical coherence tomography improves UCC detection, Nat Rev Urol. 7 (2010) 6. http://dx.doi.org/10.1038/nrurol.2009.248.

[67] B.J. Vakoc, D. Fukumura, R.K. Jain, B.E. Bouma, Cancer imaging by optical coherence tomography: preclinical progress and clinical potential, Nat Rev Cancer. 12 (2012) 363-368. http://dx.doi.org/10.1038/nrc3235.

[68] J.W. Tunnell, a S. Haka, S. a McGee, J. Mirkovic, M.S. Feld, Diagnostic tissue spectroscopy and its applications to gastrointestinal endoscopy, Tech. Gastrointest. Endosc. 5 (2003) 65-73. doi:10.1053/tgie.2003.50004.

[69] C. Zhu, G.M. Palmer, T.M. Breslin, J. Harter, N. Ramanujam, Diagnosis of breast cancer using fluorescence and diffuse reflectance spectroscopy: a Monte-Carlo-model-based approach, J. Biomed. Opt. 13 (2008) 34015. doi:10.1117/1.2931078.

[70] Y. Zhu, T. Fearn, G. Mackenzie, B. Clark, J.M. Dunn, I.J. Bigio, S.G. Bown, L.B. Lovat, Elastic scattering spectroscopy for detection of cancer risk in Barrett's esophagus: experimental and clinical validation of error removal by orthogonal subtraction for increasing accuracy, J. Biomed. Opt. 14 (2009) 44022. doi:10.1117/1.3194291.

[71] G.S. Bumbrah, R.M. Sharma, Raman spectroscopy - Basic principle, instrumentation and selected applications for the characterization of drugs of abuse, Egypt. J. Forensic Sci. (2015). doi:10.1016/j.ejfs.2015.06.001.

[72] K. Kong, C. Kendall, N. Stone, I. Notingher, Raman spectroscopy for medical diagnostics From in-vitro biofluid assays to in-vivo cancer detection., Adv. Drug Deliv. Rev. 89 (2015) 121134. doi:10.1016/j.addr.2015.03.009.

[73] E. Brauchle, K. Schenke-Layland, Raman spectroscopy in biomedicine - non-invasive in vitro analysis of cells and extracellular matrix components in tissues, Biotechnol. J. 8 (2013) 288297. doi:10.1002/biot.201200163.

[74] R.H. Clarke, E.B. Hanlon, J.M. Isner, H. Brody, Laser Raman spectroscopy of calcified atherosclerotic lesions in cardiovascular tissue, Appl. Opt. 26 (1987) 3175-3177. doi:10.1364/AO.26.003175.

[75] M.G. Shim, L.W.K. Song, N.E. Marcon, B.C. Wilson, In vivo Near-infrared Raman Spectroscopy: Demonstration of Feasibility During Clinical Gastrointestinal Endoscopy १, Photochem. Photobiol. 72 (2000) 146-150. doi:10.1562/0031-8655(2000)0720146IVNIRS2.0.CO2.

[76] S. Coda, P.D. Siersema, G.W.H. Stamp, A. V Thillainayagam, Biophotonic endoscopy: a review of clinical research techniques for optical imaging and sensing of early gastrointestinal cancer, 
Endosc. Int. Open. 3 (2015) E380-E392. doi:10.1055/s-0034-1392513.

[77] C.E. Riva, M. Geiser, B.L. Petrig, Ocular blood flow assessment using continuous laser Doppler flowmetry., Acta Ophthalmol. 88 (2010) 622-629. doi:10.1111/j.1755-3768.2009.01621.x.

[78] H. Jafarzadeh, Laser Doppler flowmetry in endodontics: a review, Int. Endod. J. 42 (2009) 476-490. doi:10.1111/j.1365-2591.2009.01548.x.

[79] a V Dunaev, V. V Sidorov, a I. Krupatkin, I.E. Rafailov, S.G. Palmer, N. a Stewart, S.G. Sokolovski, E.U. Rafailov, Investigating tissue respiration and skin microhaemocirculation under adaptive changes and the synchronization of blood flow and oxygen saturation rhythms., Physiol. Meas. 35 (2014) 607-621. doi:10.1088/0967-3334/35/4/607.

[80] A. V Dunaev, E. a Zherebtsov, D. a Rogatkin, N. a Stewart, S.G. Sokolovski, E.U. Rafailov, Novel measure for the calibration of laser Doppler flowmetry devices, 8936 (2014) 1-7. doi:10.1117/12.2035651.

[81] S. Palmer, S.G. Sokolovski, E. Rafailov, G. Nabi, Technologic developments in the field of photonics for the detection of urinary bladder cancer, Clin. Genitourin. Cancer. 11 (2013) 390-396. doi:10.1016/j.clgc.2013.04.016.

[82] D.M. Hemingway, W.J. Angerson, J.H. Anderson, J.A. Goldberg, C.S. McArdle, T.G. Cooke, Monitoring blood flow to colorectal liver metastases using laser Doppler flowmetry: the effect of angiotensin II., Br. J. Cancer. 66 (1992) 958-960.

http://www.ncbi.nlm.nih.gov/pmc/articles/PMC1977985/.

[83] M.S. Heier, T. Nilsen, V. Graver, N. Aass, S.D. Fosså, Raynaud's phenomenon after combination chemotherapy of testicular cancer, measured by laser Doppler flowmetry. A pilot study., Br. J. Cancer. 63 (1991) 550-552.

http://www.ncbi.nlm.nih.gov/pmc/articles/PMC1972340/.

[84] B. Alsbjörn, J. Micheels, B. Sørensen, Laser Doppler Flowmetry Measurements of Superficial Dermal, Deep Dermal and Subdermal Burns, Scand. J. Plast. Reconstr. Surg. 18 (1984) 75-79. doi:10.3109/02844318409057406.

[85] V. V Dremin, V. V Sidorov, A.I. Krupatkin, G.R. Galstyan, N. Irina, A.I. Zherebtsova, E.A. Zherebtsov, A. V Dunaev, N. Zera, The blood perfusion and NADH / FAD content combined analysis in patients with diabetes foot, SPIE Proc. 9698 (2016) 969810.

[86] H. Liu, M. Kohl-Bareis, X. Huang, Design of a tissue oxygenation monitor and verification on human skin, in: 2011: p. 80871Y-80871Y-10. http://dx.doi.org/10.1117/12.889197.

[87] J.M. Murkin, M. Arango, Near-infrared spectroscopy as an index of brain and tissue oxygenation, Br. J. Anaesth. . 103 (2009) i3-i13.

http://bja.oxfordjournals.org/content/103/suppl_1/i3.abstract.

[88] T.W.L. Scheeren, P. Schober, L.A. Schwarte, Monitoring tissue oxygenation by near infrared spectroscopy (NIRS): background and current applications, J. Clin. Monit. Comput. 26 (2012) 279-287. doi:10.1007/s10877-012-9348-y.

[89] A. Gillenwater, R. Jacob, R. Richards-Kortum, Fluorescence spectroscopy: A technique with potential to improve the early detection of aerodigestive tract neoplasia, Head Neck. 20 (1998) 556-562. doi:10.1002/(SICI)1097-0347(199809)20:6<556::AID-HED11>3.0.CO;2-O.

[90] L. Bachmann, Fluorescence Spectroscopy of Biological Tissues, Appl. Spectrosc. Rev. 41 (2006) 575-590. doi:10.1080/05704920600929498.

[91] K. Sudhakar, M. Vanderkoois, Fluorescent Derivatives of Human Hemoglobin, (1994). 
[92] S. Gao, X. Lan, Y. Liu, Z. Shen, J. Lu, X. Ni, Characteristics of blood fluorescence spectra using low-level, 457.9-nm excitation from Ar+ laser, Chinese Opt. Lett. 2 (2004) 160-161. http://col.osa.org/abstract.cfm?URI=col-2-3-160.

[93] N. Ramanujam, Fluorescence Spectroscopy of Neoplastic and Non-Neoplastic Tissues, Neoplasia. 2 (2000) 89-117. http://www.ncbi.nlm.nih.gov/pmc/articles/PMC1531869/.

[94] A. V Dunaev, V. V Dremin, E.A. Zherebtsov, I.E. Rafailov, K.S. Litvinova, S.G. Palmer, N.A. Stewart, S.G. Sokolovski, E.U. Rafailov, Individual variability analysis of fluorescence parameters measured in skin with different levels of nutritive blood flow., Med. Eng. Phys. 37 (2015) 574-83. doi:10.1016/j.medengphy.2015.03.011.

[95] L. Marcu, M.C. Fishbein, J.-M.I. Maarek, W.S. Grundfest, Discrimination of Human Coronary Artery Atherosclerotic Lipid-Rich Lesions by Time-Resolved Laser-Induced Fluorescence Spectroscopy, Arterioscler. Thromb. Vasc. Biol. . 21 (2001) 1244-1250. doi:10.1161/hq0701.092091.

[96] M.A. Calfon, C. Vinegoni, V. Ntziachristos, F.A. Jaffer, Intravascular near-infrared fluorescence molecular imaging of atherosclerosis: toward coronary arterial visualization of biologically high-risk plaques, J. Biomed. Opt. 15 (2010) 11107. doi:10.1117/1.3280282.

[97] K. Pandey, A. Pradhan, A. Agarwal, A. Bhagoliwal, N. Agarwal, Fluorescence Spectroscopy: A New Approach in Cervical Cancer, J. Obstet. Gynaecol. India. 62 (2012) 432-436. doi:10.1007/s13224-012-0298-6.

[98] K.T. Schomacker, J.K. Frisoli, C.C. Compton, T.J. Flotte, J.M. Richter, N.S. Nishioka, T.F. Deutsch, Ultraviolet laser-induced fluorescence of colonic tissue: Basic biology and diagnostic potential, Lasers Surg. Med. 12 (1992) 63-78. doi:10.1002/lsm.1900120111.

[99] I. Georgakoudi, B.C. Jacobson, J. Van Dam, V. Backman, M.B. Wallace, M.G. Müller, Q. Zhang, K. Badizadegan, D. Sun, G.A. Thomas, L.T. Perelman, M.S. Feld, Fluorescence, reflectance, and light-scattering spectroscopy for evaluating dysplasia in patients with Barrett's esophagus, Gastroenterology. 120 (2001) 1620-1629. doi:10.1053/gast.2001.24842.

[100] K.S. Litvinova, D. a Rogatkin, O. a Bychenkov, V.I. Shumskiy, Chronic Hypoxia as a Factor of Enhanced Autofluorescence of Endogenous Porphyrins in Soft Biological Tissues, Methods. 7547 (2010) 1-6. doi:10.1117/12.853512.

[101] A. Shahzad, M. Knapp, M. Edetsberger, M. Puchinger, E. Gaubitzer, G. Köhler, Diagnostic Application of Fluorescence Spectroscopy in Oncology Field: Hopes and Challenges, Appl. Spectrosc. Rev. 45 (2010) 92-99. doi:10.1080/05704920903435599.

[102] S. Palmer, K. Litvinova, E.U. Rafailov, G. Nabi, Discrimination of healthy and cancer cells of the bladder by metabolic state, based on autofluorescence, 9303 (2015) 93030T. doi:10.1117/12.2077218.

[103] A. V. Dunaev, V. V. Dremin, E. a. Zherebtsov, I.E. Rafailov, K.S. Litvinova, S.G. Palmer, N. a. Stewart, S.G. Sokolovski, E.U. Rafailov, Individual variability analysis of fluorescence parameters measured in skin with different levels of nutritive blood flow, Med. Eng. Phys. 0 (2015) 1-10. doi:10.1016/j.medengphy.2015.03.011.

[104] O. Castro-e-Silva, A.K. Sankarankutty, R.B. Correa, J. Ferreira, J.D. Vollet Filho, C. Kurachi, V.S. Bagnato, Autofluorescence Spectroscopy in Liver Transplantation: Preliminary Results From a Pilot Clinical Study, Transplant. Proc. 40 (2008) 722-725. doi:http://dx.doi.org/10.1016/j.transproceed.2008.03.005.

[105] R. Kramme, Rüdiger, Hoffmann, Klaus-Peter, Pozos, Springer Handbook of Medical 
Technology, 2011. doi:10.1007/978-3-540-74658-4.

[106] N.T. Clancy, G.E. Nilsson, C.D. Anderson, M.J. Leahy, A new device for assessing changes in skin viscoelasticity using indentation and optical measurement, Ski. Res. Technol. 16 (2010) 210-228. doi:10.1111/j.1600-0846.2010.00433.x.

[107] B. Jakoby, M.J. Vellekoop, U. Timm, G. Leen, E. Lewis, D. McGrath, J. Kraitl, H. Ewald, Eurosensor XXIV ConferenceNon-invasive optical real-time measurement of total hemoglobin content, Procedia Eng. 5 (2010) 488-491.

doi:http://dx.doi.org/10.1016/j.proeng.2010.09.153.

[108] D. a. Rogatkin, S.G. Sokolovski, K. a. Fedorova, N. a. Stewart, V. V. Sidorov, E.U. Rafailov, Basic principles of design and functioning of multifunctional laser diagnostic system for noninvasive medical spectrophotometry, 7890 (2011) 78901H-78901H-7. doi:10.1117/12.874258.

[109] R.G. HAHN, Y. LI, J. ZDOLSEK, Non-invasive monitoring of blood haemoglobin for analysis of fluid volume kinetics, Acta Anaesthesiol. Scand. 54 (2010) 1233-1240. doi:10.1111/j.13996576.2010.02321.x.

[110] D.A. Colquhoun, K.T. Forkin, M.E. Durieux, R.H. Thiele, Ability of the Masimo pulse COOximeter to detect changes in hemoglobin, J. Clin. Monit. Comput. 26 (2012) 69-73. doi:10.1007/s10877-012-9335-3.

[111] A. V Dunaev, E. a Zherebtsov, D. a Rogatkin, N. a Stewart, S.G. Sokolovski, E.U. Rafailov, Substantiation of medical and technical requirements for noninvasive spectrophotometric diagnostic devices., J. Biomed. Opt. 18 (2013) 107009. doi:10.1117/1.JBO.18.10.107009.

[112] I. V. Meglinski, S.J. Matcher, Quantitative assessment of skin layers absorption and skin reflectance spectra simulation in the visible and near-infrared spectral regions., Physiol. Meas. 23 (2002) 741-753. doi:10.1088/0967-3334/23/4/312.

[113] A. Doronin, I. Meglinski, Online object oriented Monte Carlo computational tool for the needs of biomedical optics, Biomed. Opt. Express. 2 (2011) 2461. doi:10.1364/BOE.2.002461.

[114] I. Fredriksson, C. Fors, J. Johansson, Laser Doppler Flowmetry - a Theoretical Framework, 2007. http://www.imt.liu.se/bit/ldf/ldf.pdf.

[115] V. Loschenov, V. Konov, A. Prokhorov, Photodynamic therapy and fluorescence diagnostics, Laser Phys. 10 (2000) 1188-1207. http://www.cytoluminator.com/cancer-photodynamictherapy/PDT and fluorescent imaging.pdf.

[116] V. V Tuchin, X. Xu, R.K. Wang, Dynamic optical coherence tomography in studies of optical clearing, sedimentation, and aggregation of immersed blood, Appl. Opt. 41 (2002) 258-271. doi:10.1364/AO.41.000258.

[117] R.R. Anderson, J.A. Parrish, The Optics of Human Skin, J. Invest. Dermatol. 77 (1981) 13-19. doi:http://dx.doi.org/10.1111/1523-1747.ep12479191.

[118] X. Pan, S. Tang, A. Guo, C. Liu, J. Zhu, Multifunctional Wave Diagnostics Based on Coherent Modulation Imaging in High Power Laser Facilities, in: Imaging Appl. Opt. 2017 (3D, AIO, COSI, IS, MATH, pcAOP), Optical Society of America, 2017: p. JTu5A.37.

http://www.osapublishing.org/abstract.cfm?URI=AIO-2017-JTu5A.37.

[119] A. Mayevsky, B. Chance, Oxidation-reduction states of NADH in vivo: From animals to clinical use, Mitochondrion. 7 (2007) 330-339. doi:10.1016/j.mito.2007.05.001.

[120] E.U. Rafailov, K.S. Litvinova, S.G. Sokolovski, Towards novel compact laser sources for non- 
invasive diagnostics and treatment, in: 2015: p. 95500G-95500G-12.

http://dx.doi.org/10.1117/12.2193777.

[121] A. V Dunaev, V. V Sidorov, N.A. Stewart, S.G. Sokolovski, E.U. Rafailov, Laser reflectance oximetry and Doppler flowmetry in assessment of complex physiological parameters of cutaneous blood microcirculation, in: 2013: pp. 857205-857209.

http://dx.doi.org/10.1117/12.2001797.

[122] B. Chance, B. Schoener, R. Oshino, F. Itshak, Y. Nakase, Oxidation-reduction ratio studies of mitochondria in freeze-trapped samples. NADH and flavoprotein fluorescence signals., J. Biol. Chem. . 254 (1979) 4764-4771. http://www.jbc.org/content/254/11/4764.abstract.

[123] R.L. Veech, The determination of the redox states and phosphorylation potential in living tissues and their relationship to metabolic control of disease phenotypes, Biochem. Mol. Biol. Educ. 34 (2006) 168-179. doi:10.1002/bmb.2006.49403403168.

[124] A.I. Krupatkin, V. V. Sidorov, V. V. Dremin, A. V. Dunaev, I.N. Novikova, S. Zhu, G. Nabi, K.S. Litvinova, A.P. Baklanova, R.M. Bakshaliev, S. a. Ravcheev, Evaluating adaptation options of microcirculatory-tissue systems based on the physiological link of nutritive blood flow and redox ratio, 9448 (2015) 944803. doi:10.1117/12.2179560.

[125] A.A.H. Vladimir V. Ghukasyan, Natural Biomarkers for Cellular Metabolism Biology, Techniques, and Applications, 2014.

[126] N.A. Stewart, A.V. Dunaev, S.G. Sokolovski, V.V. Sidorov, E.U. Rafailov, Multi-parameter analysis in blood circulation and perfusion based diagnostics, 15th Int. Conf. Laser Opt. (2012) 78901.

[127] V. V Dremin, E.A. Zherebtsov, I.E. Rafailov, A.Y. Vinokurov, I.N. Novikova, A.I. Zherebtsova, K.S. Litvinova, A. V Dunaev, The development of attenuation compensation models of fluorescence spectroscopy signals, in: 2016: p. 99170Y-99170Y-6.

http://dx.doi.org/10.1117/12.2229451.

[128] N. Akbar, S. Sokolovski, a. Dunaev, J.J.F. Belch, E. Rafailov, F. Khan, In vivo noninvasive measurement of skin autofluorescence biomarkers relate to cardiovascular disease in mice, J. Microsc. 255 (2014) 42-48. doi:10.1111/jmi.12135.

[129] K.S. Litvinova, S. Ahmad, K. Wang, I.E. Rafailov, S.G. Sokolovski, L. Zhang, E.U. Rafailov, A. Ahmed, A pilot study using laser-based technique for non-invasive diagnostics of hypertensive conditions in mice, in: 2016: p. 96893H-96893H-8. http://dx.doi.org/10.1117/12.2213026.

[130] J.M. Roberts, Endothelial dysfunction in preeclampsia, Semin. Reprod. Endocrinol. 16 (1998) 5-15. http://europepmc.org/abstract/MED/9654603.

[131] V. V. Andrukhina, K.S. Litvinova, A.. A. Nikitin, N.Z. Spiridonova, D.A. Rogatkin, The first experience in estimation of basal cell carcinoma cryoresistence using the noninvasive spectrophotometry, 7547 (2010).

[132] I.J. Bigio, J.R. Mourant, Ultraviolet and visible spectroscopies for tissue diagnostics: fluorescence spectroscopy and elastic-scattering spectroscopy., Phys. Med. Biol. 42 (1997) 803-814. doi:10.1088/0031-9155/42/5/005.

[133] B. Wu, S.K. Gayen, M. Xu, Fluorescence spectroscopy using excitation and emission matrix for quantification of tissue native fluorophores and cancer diagnosis, in: 2014: p. 89261M89261M-8. http://dx.doi.org/10.1117/12.2040985. 
[134] D.S.E. Laura Marcu, Paul M.W. French, Fluorescence lifetime spectroscopy and imaging : principles and applications in biomedical diagnostics, 2014.

[135] I. Rafailov, S. Palmer, K. Litvinova, V. Dremin, A. Dunaev, G. Nabi, A novel excitation-emission wavelength model to facilitate the diagnosis of urinary bladder diseases, 9303 (2015) 93030W. doi:10.1117/12.2077554.

[136] I.E. Rafailov, V. V. Dremin, K.S. Litvinova, A. V. Dunaev, S.G. Sokolovski, E.U. Rafailov, Computational model of bladder tissue based on its measured optical properties, J. Biomed. Opt. 21 (2016) 25006. doi:10.1117/1.JBO.21.2.025006.

[137] I. Georgakoudi, B.C. Jacobson, M.G. Müller, E.E. Sheets, K. Badizadegan, D.L. Carr-Locke, C.P. Crum, C.W. Boone, R.R. Dasari, J. Van Dam, M.S. Feld, NAD(P)H and collagen as in vivo quantitative fluorescent biomarkers of epithelial precancerous changes, Cancer Res. 62 (2002) 682-687.

[138] M.G. Muller, T.A. Valdez, I. Georgakoudi, V. Backman, C. Fuentes, S. Kabani, N. Laver, Z. Wang, C.W. Boone, R.R. Dasari, S.M. Shapshay, M.S. Feld, Spectroscopic detection and evaluation of morphologic and biochemical changes in early human oral carcinoma, Cancer. 97 (2003) 1681-1692. doi:10.1002/cncr.11255.

[139] O. Aboumarzouk, R. Valentine, R. Buist, S. Ahmad, G. Nabi, S. Eljamel, H. Moseley, S.G. Kata, Laser-induced autofluorescence spectroscopy: Can it be of importance in detection of bladder lesions?, Photodiagnosis Photodyn. Ther. 12 (2015) 76-83.

doi:10.1016/j.pdpdt.2014.12.003. 